\title{
Directly Printable Organic ASK Based Chipless RFID Tag for IoT Applications
}

\author{
Ayesha HABIB ${ }^{1}$, Sohaira ANSAR ${ }^{1}$, Adeel AKRAM ${ }^{1}$, Muhammad Awais AZAM ${ }^{1}$, \\ Yasar AMIN ${ }^{1,2}$, Hannu TENHUNEN ${ }^{2,3}$ \\ ${ }^{1}$ ACTSENA Research Group, University of Engineering and Technology, 47050- Taxila, Pakistan \\ 2 iPack VINN Excellence Center, Royal Institute of Technology, SE-16440, Stockholm, Sweden \\ ${ }^{3}$ TUCS, University of Turku, Turku-20520, Finland \\ ayesha.habib@uettaxila.edu.pk
}

Submitted August 9, 2016 / Accepted March 21, 2017

\begin{abstract}
A chipless RFID tag with unique ASK encoding technique is presented in this paper. The coding efficiency is enhanced regarding tag capacity. The amplitude variations of the backscattered RFID signal is used for encoding data instead of OOK. Strips of different widths are used to have amplitude variations. The ASK technique is applied using three different substrates of Kapton ${ }^{\circledR} H N, P E T$, and paper. To incorporate ASK technique, dual polarized rhombic shaped resonators are designed. These tags operate in the frequency range of 3.1-10.6 GHz with size of $70 \times 42 \mathrm{~mm}^{2}$. The presented tags are flexible and offer easy printability. The paper-based decomposable organic tag appears as an ultra low-cost solution for wide scale tracking. This feature enables them to secure a prominent position in the emerging fields of IoT and green electronics.
\end{abstract}

\section{Keywords}

Internet-of-Things (IoT), Radio Frequency Identification (RFID), chipless, Amplitude Shift Keying (ASK), resistive strip, coupling, damping

\section{Introduction}

A fully connected network in which every entity, whether physical or virtual, can be accessed at any time, any place using any route defines IoT, the advancement in embedded systems and nanotechnology has provided automated decisions and all in one platform capability to the IoT [1]. IoT consists of smart devices of time like smartphones, tablets, surveillance systems, industrial equipment, field operation devices, automobiles, etc. [2], [3]. Realization of such smaller, powerful processing devices with onboard sensing capabilities makes IoT an important beacon of this tech-era. These smart devices are integrating the concept of data encoding and sensing resulting in an intelligent interaction. IoT allows automated systems to immediately response according to information provided by these smart devices [4], [6]. Now this information can be easily accessed through internet and decisions can be made remotely [7]. IoT has found its applications in different areas including health, education, industry, traveling, surveillance systems, home, business, geographical survey, mining, etc.

To implement IoT, the ubiquitous network is required to manage the whole network remotely. Wireless Sensor Network (WSN) provides the required medium for management and communication of smart nodes. Hence, on primitive level IoT works by implementing WSN techniques. Furthermore, the task of identification and autonomous tracking of smart nodes is carried out by RFID.

The RFID system works using radio waves as their communication medium. A general RFID comprises of RFID interrogators, RFID transponders/tags, and middleware system. The transponders are mounted on the objects being tracked or monitored. These tags in the vicinity of the reader are activated by the stimulus initiated by reader side. This stimulus is an electromagnetic (EM) signal from reader towards transponder for its activation. The required data is encoded by modulating this incident EM signal [8]. The encoded signal is backscattered towards interrogator. This received signal is forwarded to middleware software for further processing.

RFID tags can be majorly classified on the basis of the power facility and modulating entity. The availability of power supply classifies these tags into active and passive ones. Active tags offer long read range, possess on board battery but they are expensive. The cost of a tag is a matter of concern while choosing RFID as an identification technique. To replace the low-cost line-of-sight barcode technology, RFID should appear as cost effective solution. In this regard, the cost of a passive tag is quite low as compared to active ones due to the absence of power supply. So, while choosing a RFID tag for our system, a tradeoff is done between their prices and read range [9]. This feature of passive tags allows a cost effective 
solution for wide scale deployment of tags in the environment [10]. The classification of RFID tags can also be done on the basis of the modulator. The modulation of the incident signal is responsible for generating EM response of the tag. The properties of reflected signal are different from incident signal due to modulation. On the basis of this difference, reader interprets encoded message. In this perspective, the mounted tag over the object may be chip based or chipless.

In case of chip-based tags, the transponder device consists of two parts 1) scatterer, 2) encoder. Such tags use Application Specific Integrated Circuit or silicon chip as an encoder. While the transmission and reception of EM signals is done through scatterer or the antenna part. Silicon chip is responsible for encoding the information through modulation. Through backscattering phenomena, the reader receives its encoded message. On the other hand, chipless tags appear as a cost-effective solution that eliminates the need for costly silicon chip [11]. The antenna part performs the modulation of the signal as well as the transmission and reception of signals. Moreover, these energy efficient tags harvest RF energy from the transmitted signal and act like rectenna [12]. Hence, the chipless tag dually acts as scatterer as well as an encoder.

Some common examples of cost effective tags include embedding them in bank notes, passports, toll cards, clothes, shoe soles, on locomotives, helmets of miners, etc. where they are replacing the barcode technology efficiently. Chipless RFID tags are low cost, easily printable, lightweight, energy efficient and can bear high temperature and pressures. They can be easily embedded in different spying applications. They can be equipped with sensing materials and can act as very simple sensor nodes. These fascinating attributes prove chipless RFID tags to be an excellent sensor node for wireless WSN [13].

Printable chipless RFID tags may be retransmission based and backscattering based tags. Retransmission based tags are larger in size and require monopole antennas with resonators [14]. The backscattering based tags consist of only multi-resonators. Data is usually encoded in frequency, amplitude and phase, time of backscattered signal. The EM response of the backscattered signal greatly depends on the geometry and size of resonating structures [15]. On the basis of presence and absence of resonators, on-off keying (OOK) is observed as a spectral response. In this scenario, $\mathrm{x}$ resonators can produce $2^{\mathrm{x}}$ combinations for encoding of data. To further enhance this coding efficiency, amplitude variation technique of the backscattered signal can be used. This will provide more combinations i.e. more unique IDs for identification. In Amplitude Shift Keying (ASK), the data is encoded as variations in the amplitude of backscattered encoded signal while OOK is a simpler form of ASK in which absence or presence of signal depicts the ' 0 ' and ' 1 ', respectively. Hence, by opting ASK technique coding capacity of tag can be increased.
In this research, a technique is explored which can increase the coding efficiency of broadband Chipless RFID tag. More precisely, Amplitude Shift Keying (ASK) has been studied and verified through simulations. Using ASK collective data rate has been enhanced up to 24-bits that is the highest among the previously reported work up to date [16]. The tag is easily printable on the object, flexible and supports green electronics. ASK technique has been applied on tag design and analysis is performed using different substrates.

\section{Theory and Working Principle}

Broadband antennas cannot be used for signature generation. The coding efficiency of such antennas can be increased by using ASK. To excite the tag, instead of using conventional methods, the incident plane wave (circularly polarized) is applied. The circular plane wave equation for E-field,

$$
\mathbf{E}(x, y, z, t)=E_{\mathrm{o}} \mathrm{e}^{\mathrm{j}(\omega t-k z)} \hat{\mathbf{x}}+E_{\mathrm{o}} \mathrm{e}^{\mathrm{j}(\omega t-k z+\pi / 2)} \hat{\mathbf{y}} .
$$

For Radar Cross Section (RCS) measurement of chipless tag, the far-field distance is calculated by using (2), where $D$ is maximum dimension of tag and $\lambda$ is wavelength

$$
d=\frac{2 D^{2}}{\lambda}
$$

The probes are set at far-field distance to measure the RCS response. The far-field distance is calculated as $114 \mathrm{~mm}$ for the proposed design. The backscattered signal is observed by using RCS. RCS has the information of reflected wave, which tells us about the selectivity, phase, amplitude, velocity, surface area and resonance of tag. Detection range and a cross-section of the target can also be estimated with information of RCS. Frequency domain footprint based tags are frequently designed previously [17]. Mostly, OOK is used as the spectral modulation technique. Presence or absence of resonating RCS peaks determines binary ' 1 ' and ' 0 ' respectively. The capacity of encoded bits is dependent on the number of resonators. To increase data bits, the number of resonators needs to increase while maintaining a compact size. Concentric structures are also used by previous researchers to use small space [18] efficiently.

Some hybrid techniques like pulse position modulation and phase modulation are also used to increase data capacity. These methods have enhanced the capacity and greater number of objects can be tagged [19].

\subsection{Amplitude Shift Keying (ASK)}

In this research work amplitude of received signal is being observed. ASK is explored for six resonators. The overall capacity of the tag has been increased. Previously, 
ASK has been applied for three resonators in credit card size [17].

The amplitude of receiving signal is varied by using resistive strips [20]. They are acting as bridging resistance [21] and the absence of resistive strip shows infinite resistance. These strips intervene in current paths and reduce pulse height. Amplitude variations are being observed for all six scatterers using these resistive strips. Mathematically, coding capacity is calculated by using formula

$C=$

$\log _{2}\left(\left(\frac{\Delta M_{1}}{d M_{1}}+1\right)\left(\frac{\Delta M_{2}}{d M_{2}}+1\right)\left(\frac{\Delta M_{3}}{d M_{3}}+1\right)\left(\frac{\Delta M_{4}}{d M_{4}}+1\right)\left(\frac{\Delta M_{5}}{d M_{5}}+1\right)\left(\frac{\Delta M_{6}}{d M_{6}}+1\right)\right)$

Magnitude resolution $d M_{i=(1-6)}$ is a change in neighboring peaks due to the addition of resistive strip [18]. In this technique $d M_{i=(1-6)}$ is calculated by taking the difference of varying amplitudes values of neighboring peaks when flat strip width is applied and when no strip is present. Magnitude resolution for each resonator has been set after optimization and simulation observations. $\Delta M_{i=(1-6)}$ is the difference between the maximum and minimum amplitudes of the resonator on which resistive strip has been applied i.e. $\Delta M_{i}=M_{b i}-M_{a i}$. The layout of the tag design is shown in Fig. 1.

\section{Tag Design and Optimization}

The proposed tag is composed of six resonating structures. Dual rhombic loops are designed with silver conductive tracks having conductivity $9 \times 10^{6} \mathrm{~S} / \mathrm{m}$. The thickness of silver metal is kept $15 \mu \mathrm{m}$, for easy printing of the tag. The tag design having the same dimensions is analyzed for three substrates. In spite of achieving flexibility, the main purpose is to make cost effective, energy efficient tags also having admirable data encoding capacity. Resistive strips are kept $1 \mu \mathrm{m}$ thick to attain resistance of $1000 \Omega /$ sq. All tags are designed and simulated in CST STUDIO SUITE $®$. The overall dimension of tag design is $70 \times 42 \mathrm{~mm}^{2}$ shown in Fig. 1. The inkjet printing of tag is done using a table top printer based on Fujifilm Diamatix DMP2800 printer. The silver nano particle based conductive tracks are printed using Cabot conductive Ink CCI300. We took nearly eighteen multiple passes and curing has been carried out during the printing process with the help of heat gun to avoid the misalignment between the passes. In the last two passes the resistive strips has been printed. Finally, the curing was carried out for $2 \mathrm{hr}$, at $150^{\circ} \mathrm{C}$

\subsection{Realization on Kapton ${ }^{\circledR} H N$ Substrate}

Using Kapton ${ }^{\circledR} H N$ substrate tag is designed as shown in Fig. 2. The thickness of the material is $175 \mu \mathrm{m}$ with permittivity of 3.5 and loss tangent 0.004 . The larger scatterer $\mathrm{S} 1$ has resonating frequency $3.5 \mathrm{GHz}$, the second scatterer

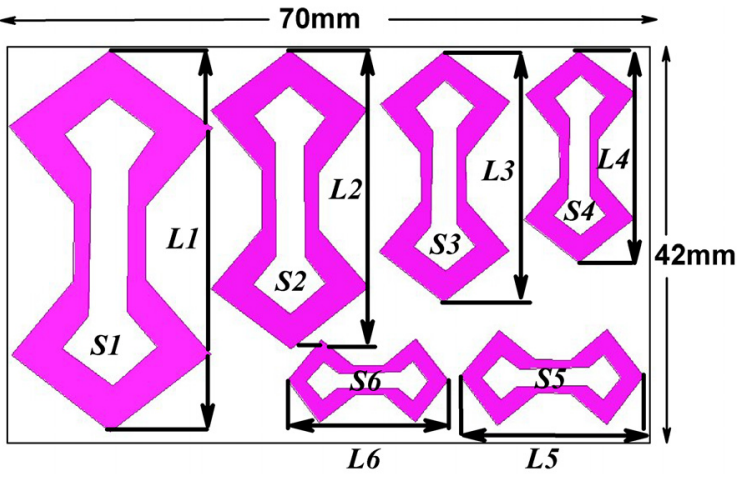

Fig. 1. Tag design dimensions. $L 1=41.21 \mathrm{~mm}$ $L 2=32.48 \mathrm{~mm}, \quad L 3=27 \mathrm{~mm}, \quad L 4=22.94 \mathrm{~mm}$, $L 5=19.97 \mathrm{~mm}, L 6=17.33 \mathrm{~mm}$.

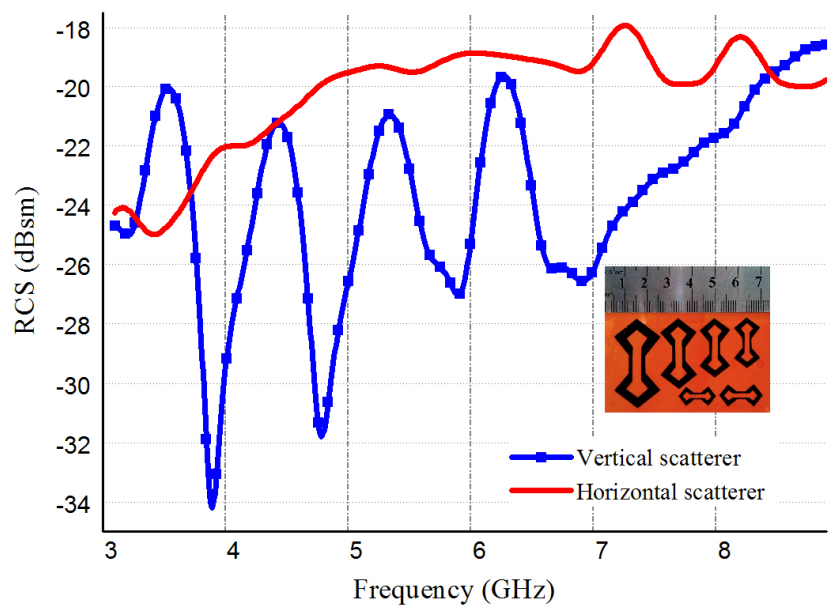

Fig. 2. Resonating peaks with no resistive strip (Kapton $\left.{ }^{\circledR} H N\right)$.

\begin{tabular}{|c|c|c|c|c|c|c|}
\hline Substrates & $\begin{array}{c}\text { R1 } \\
(\mathbf{G H z})\end{array}$ & $\begin{array}{c}\text { R2 } \\
(\mathbf{G H z})\end{array}$ & $\begin{array}{c}\text { R3 } \\
(\mathbf{G H z})\end{array}$ & $\begin{array}{c}\text { R4 } \\
(\mathbf{G H z})\end{array}$ & $\begin{array}{c}\text { R5 } \\
(\mathbf{G H z})\end{array}$ & $\begin{array}{c}\text { R6 } \\
\text { (GHz) }\end{array}$ \\
\hline Kapton ${ }^{\circledR}$ HN & 3.5 & 4.4 & 5.3 & 6.27 & 7.2 & 8.2 \\
\hline PET & 3.7 & 4.72 & 5.7 & 6.8 & 7.9 & 9.1 \\
\hline Paper & 3.42 & 4.26 & 5.23 & 6.21 & 7.08 & 8.13 \\
\hline
\end{tabular}

Tab. 1. Resonating frequencies of 1-6 scatterers for three substrates.

$\mathrm{S} 2$ resonates at $4.4 \mathrm{GHz}$, the third scatterer $\mathrm{S} 3$ resonates at $5.3 \mathrm{GHz}$, and the fourth scatterer $\mathrm{S} 4$ resonates at $6.27 \mathrm{GHz}$, the fifth scatterer $\mathrm{S} 5$ resonates at $7.2 \mathrm{GHz}$ and the sixth scatterer $\mathrm{S} 6$ resonates at $8.2 \mathrm{GHz}$ as demonstrated in Tab. 1.

\subsection{Realization on PET Substrate}

The electrical properties of PET substrate comprise of permittivity and loss tangent having values of 2.9 and 0.0025 , respectively. The thickness of material is kept to be $100 \mu \mathrm{m}$. All scatterers are designed to resonate in the band between $3.1 \mathrm{GHz}$ and $10.6 \mathrm{GHz}$. S1 resonates at $3.7 \mathrm{GHz}$, $\mathrm{S} 2$ with resonating frequency of $4.72 \mathrm{GHz}, \mathrm{S} 3$ resonates at $5.7 \mathrm{GHz}, \mathrm{S} 4$ has the resonating frequency of $6.8 \mathrm{GHz}, \mathrm{S} 5$ resonates at $7.9 \mathrm{GHz}$ and $\mathrm{S} 6$ resonates at $9.1 \mathrm{GHz}$ as shown in Tab. 1. 


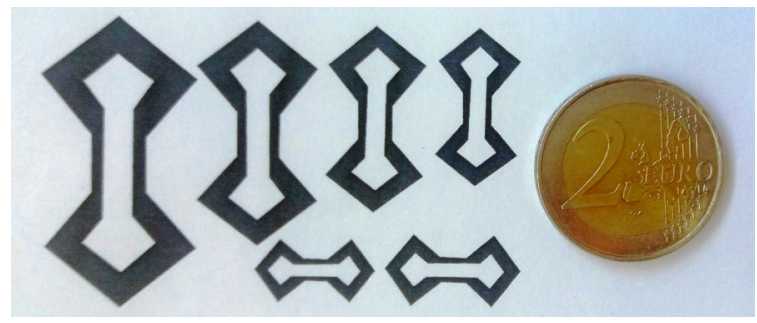

Fig. 3. Realized printed tag using paper substrate.

\subsection{Realization on Paper Substrate}

The paper substrate used in the design has thickness of $250 \mu \mathrm{m}$, permittivity of 3.3 and loss tangent of 0.777 has been selected as an electrical variant. The printed tag structure using paper substrate is shown in Fig. 3. Six scatterers S1, S2, S3, S4, S5, and S6, resonate at frequencies of $\{3.42,4.26,5.23,6.21,7.08$, and 8.13$\} \mathrm{GHz}$ respectively as shown in Tab. 1 .

\section{Results and Discussions}

In this section, the effect of adding a resistive strip on all resonators has been discussed. Coupling between resonators is avoided using position strategy [22]. All vertical resonators are not equally spaced from each other. A minimum distance of $0.8 \mathrm{~mm}$ between the $1^{\text {st }}$ and the $2^{\text {nd }}$ resonator is sufficient enough to decouple EM waves. The gap between the $2^{\text {nd }}$ and the $3^{\text {rd }}$ one is $1.9 \mathrm{~mm}$ while the $3^{\text {rd }}$ and the $4^{\text {th }}$ resonators are $2.2 \mathrm{~mm}$. Also, the space between the $5^{\text {th }}$ and $6^{\text {th }}$ resonators is kept $1.3 \mathrm{~mm}$. Resistive strips of different widths for horizontal and vertical resonators are applied to implement ASK.

Using Kapton ${ }^{\circledR} H N$ substrate, the width of the resistive strip has been varied from $0.1 \mathrm{~mm}$ to $7.5 \mathrm{~mm}$ (using 4-intervals) for $\mathrm{S} 1$, from $0.1 \mathrm{~mm}$ to $5 \mathrm{~mm}$ for $\mathrm{S} 2$, from $0.5 \mathrm{~mm}$ to $4 \mathrm{~mm}$ for $\mathrm{S} 3$ and from $0.5 \mathrm{~mm}$ to $3.5 \mathrm{~mm}$ for S4. For horizontal scatterers S5 and S6, a resistive strip of meager width is producing amplitude variations. So widths of $0.1 \mathrm{~mm}$ to $0.5 \mathrm{~mm}$ have been used for maximum amplitude variations. Amplitude variation from minimum to the maximum level for $\mathrm{S} 1$ is given in Tab. 2. The amplitude of resonating peak with resistive strip varies accordingly. Applying a resistive strip on the specific resonator also affects the amplitudes of neighboring peaks. In this way, amplitude variation analysis has been done for all resonators one by one. Damping of amplitude from maximum amplitude to minimum for the $1^{\text {st }}$ scatterer can be easily observed in Fig. 4(a). The RCS vs. frequency plots for horizontal scatterers are also shown in Fig. 4(b). Also, at the largest strip width when the amplitude of the corresponding peak is almost deteriorated, a shift in neighboring peaks occurs which is shown in Fig. 4(a). It is deduced from observation that the change in thickness of the substrate is responsible for frequency shifting behavior.

\begin{tabular}{|c|c|c|c|c|}
\hline Tags & Substrate & $\begin{array}{c}\text { Max. } \\
\text { Amplitude. } \\
\text { of S1 } \mathbf{M}_{\mathbf{a}} \text { (dB) }\end{array}$ & $\begin{array}{c}\text { Min. } \\
\text { Amplitude. } \\
\text { of S1 } \mathbf{M}_{\mathbf{b}} \\
\mathbf{( d B )}\end{array}$ & $\begin{array}{c}\text { Data capacity } \\
\text { of tag (bits) }\end{array}$ \\
\hline Tag 1 & Kapton $(\mathrm{HN}$ & -20.09 & -24.6 & 16 \\
\hline Tag 2 & PET & -19.89 & -24.14 & 21 \\
\hline Tag 3 & Paper & -21.22 & -25.30 & 24 \\
\hline
\end{tabular}

Tab. 2. Maximum and minimum amplitude variations and corresponding data capacity.

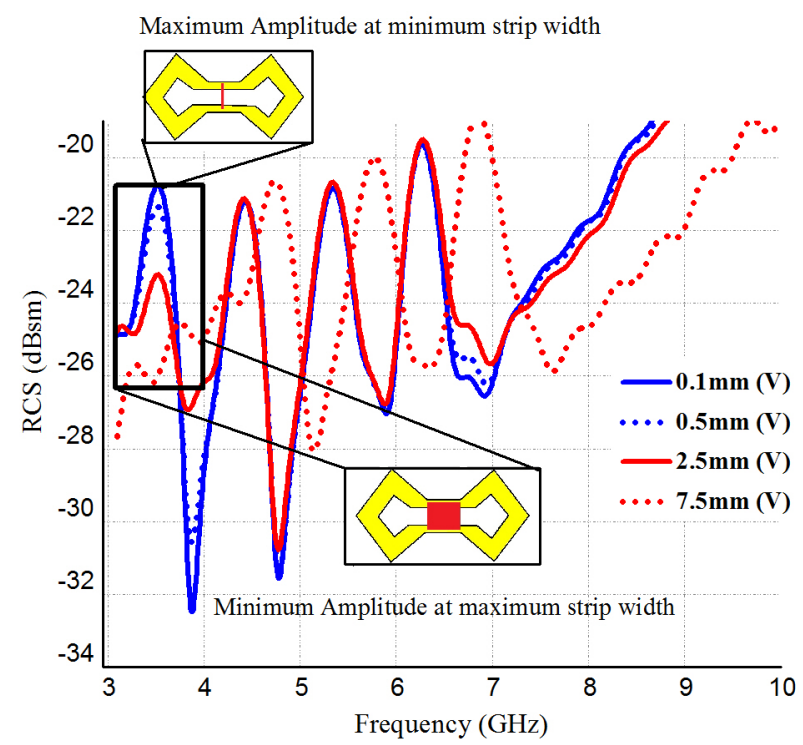

(a)

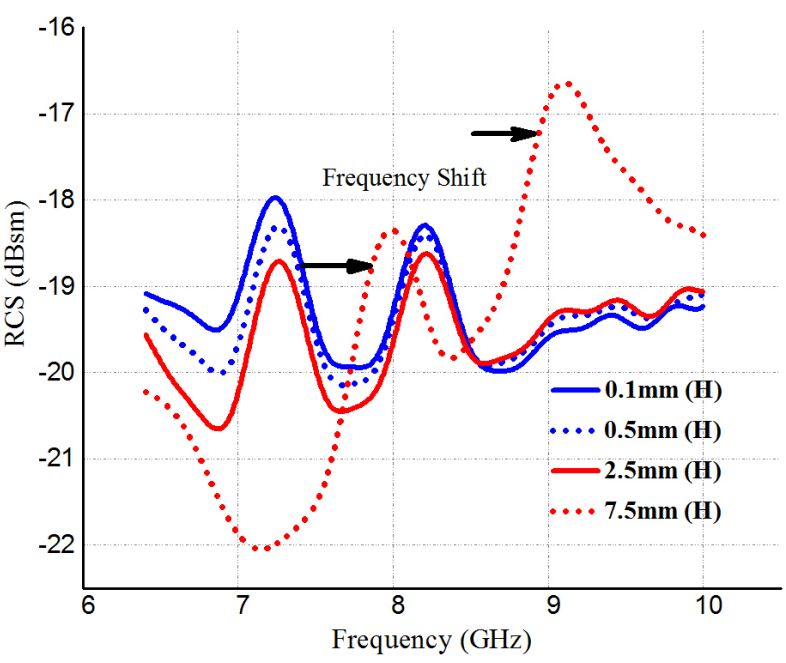

(b)

Fig. 4. Simulation results for ASK in $\mathrm{S} 1$ for Kapton ${ }^{\circledR} H N$ substrate. (a) Vertical scatterers showing ASK in S1. (b) Horizontal scatterers.

The surface current distribution for two different frequencies is being observed. Figure 5(a) shows the induced surface current corresponding to scatterer having the largest dimension and Figure 5(b) shows the mapping of EM waves on the scatterer having the smallest dimension for the lowest and highest frequencies, respectively. 


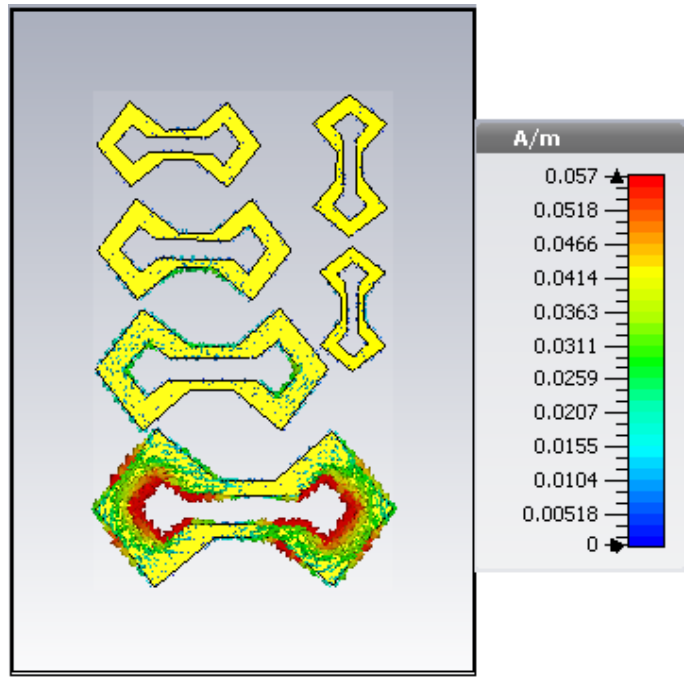

(a)

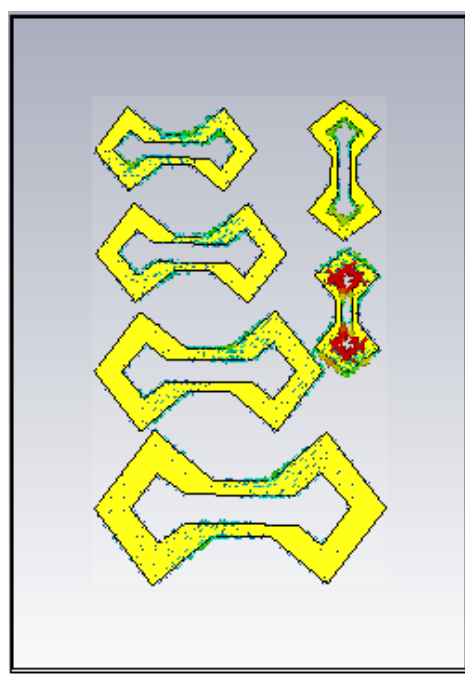

(b)

Fig. 5. Current distribution. (a) For the lowest frequency. (b) For the highest frequency.

For measuring RCS of a tag, the controlled testing environment is used. The whole setup comprises of two horn antennas, one for reception and other for transmission, Vector Network Analyzer R\&S ${ }^{\circledR}$ ZVL13 and Chipless RFID tag. The measurement setup is in accordance with previously used standard measurement procedure as mentioned in detail elsewhere [23]. The tag design is manufactured and experimentally tested for five prototypes using each substrate for analysis of reliability parameters. In RCS values tag has tolerance of $\pm 0.01 \%$ and $\pm 0.25 \%$ in the desired frequency band as shown in Fig. 6.

Fully damped RCS response flattens the peak, and the width of the resistive strip at this point is known as flat peak strip width as shown in Tab. 3. For the maximum width of the resistive strip, the resistance would be low. Similarly for the minimum width of the resistive strip, the resistance becomes high and this can also be understood from (4)

$$
R=\frac{\rho L}{A}
$$

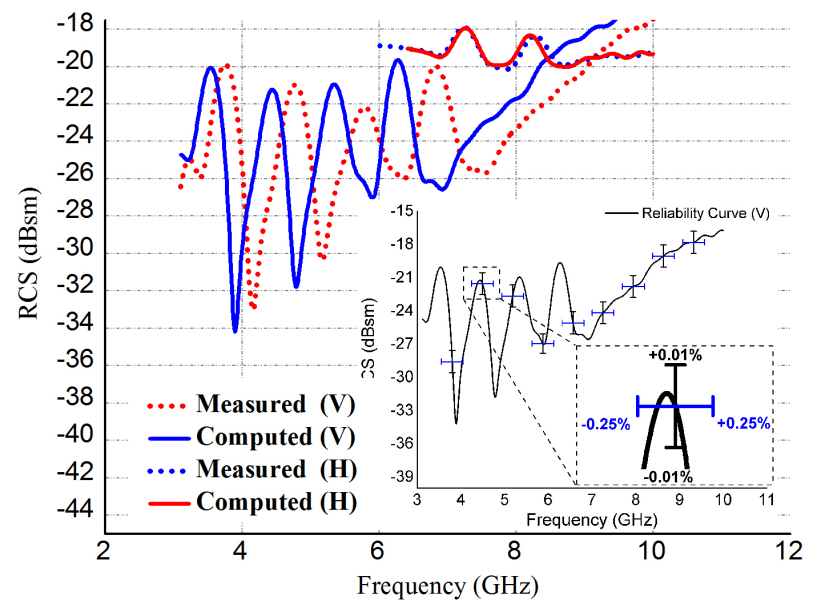

Fig. 6. Measured and RCS reliability graph of the tag.

\begin{tabular}{|c|c|c|c|c|c|c|}
\hline Substrate & $\begin{array}{c}\text { S1 } \\
(\mathbf{m m})\end{array}$ & $\begin{array}{c}\text { S2 } \\
(\mathbf{m m})\end{array}$ & $\begin{array}{c}\text { S3 } \\
(\mathbf{m m})\end{array}$ & $\begin{array}{c}\text { S4 } \\
(\mathbf{m m})\end{array}$ & $\begin{array}{c}\text { S5 } \\
(\mathbf{m m})\end{array}$ & $\begin{array}{c}\text { S6 } \\
(\mathbf{m m})\end{array}$ \\
\hline Kapton ${ }^{\circledR H N}$ & 7.5 & 5 & 4 & 3.5 & 0.5 & 0.5 \\
\hline PET & 7 & 3 & 3 & 2.5 & 0.5 & 0.4 \\
\hline Paper & 6 & 2 & 2.5 & 2.5 & 0.4 & 0.4 \\
\hline
\end{tabular}

Tab. 3. Maximum widths of the resistive strip for all scatterers giving flat peak response.

where $L$ is the length of the resistive strip, $\rho$ is resistivity of material and $A$ is the cross-sectional area of the strip. It is experimentally found that the capacity of the tag increases by having more amplitude levels through resistive strip width variations. The amount of amplitude variations of neighboring peaks, i.e. magnitude resolution $\left(\mathrm{dM}_{i}\right)$ is dependent on the substrate and ultimately effects data coding capacity. All data values are collectively shown in Tab. 4 for mathematical calculations. By putting values in (3), capacity of Kapton ${ }^{\circledR} \mathrm{HN}$ is calculated to be 16-bits.

$$
\begin{aligned}
& C=\log _{2}\left[\left(\left(\frac{(24.6-20.09)}{0.58}\right)+1\right) \cdot\left(\left(\frac{(25.01-21.8)}{0.362}\right)+1\right) \cdot\right. \\
& \left(\left(\frac{(24.06-22.25)}{0.339}\right)+1\right) \cdot\left(\left(\frac{(24.3-19.6)}{0.296}+1\right) \cdot\right. \\
& \left.\left(\left(\frac{(19.08-17.9)}{0.45}\right)+1\right) \cdot\left(\left(\frac{(19.4-18.3)}{1.244}+1\right)\right)\right]=16 \text { bits. }
\end{aligned}
$$

In PET substrate-based tag, resistive strip widths are varied from $0.1 \mathrm{~mm}$ to $7 \mathrm{~mm}$ for $\mathrm{S} 1$, from $0.1 \mathrm{~mm}$ to $3 \mathrm{~mm}$ for $\mathrm{S} 2$, from $0.1 \mathrm{~mm}$ to $3 \mathrm{~mm}$ for $\mathrm{S} 3$, from $0.1 \mathrm{~mm}$ to $2.5 \mathrm{~mm}$ for $\mathrm{S} 4$, from $0.1 \mathrm{~mm}$ to $0.5 \mathrm{~mm}$ for $\mathrm{S} 5$ and from $0.1 \mathrm{~mm}$ to $0.4 \mathrm{~mm}$ for S6. From Fig. 7(a), ASK of the PET-based tag can be easily understood for S1.

Figure 7(b) shows the RCS response of horizontal scatterers using PET substrate. The resistive strip width and the size of the resonator are interlinked with each other. Strip widths are decreasing as the sizes of resonators decrease. For example the $1^{\text {st }}$ scatterer (S1) at the width of $7 \mathrm{~mm}$ gives a flat peak response and the $6^{\text {th }}$ scatterer (S6) gives a flat peak at $0.4 \mathrm{~mm}$ for PET. Table 3 shows a comparison of these values. It is being analyzed that using PET substrate there is no shift in neighboring peaks which re- 


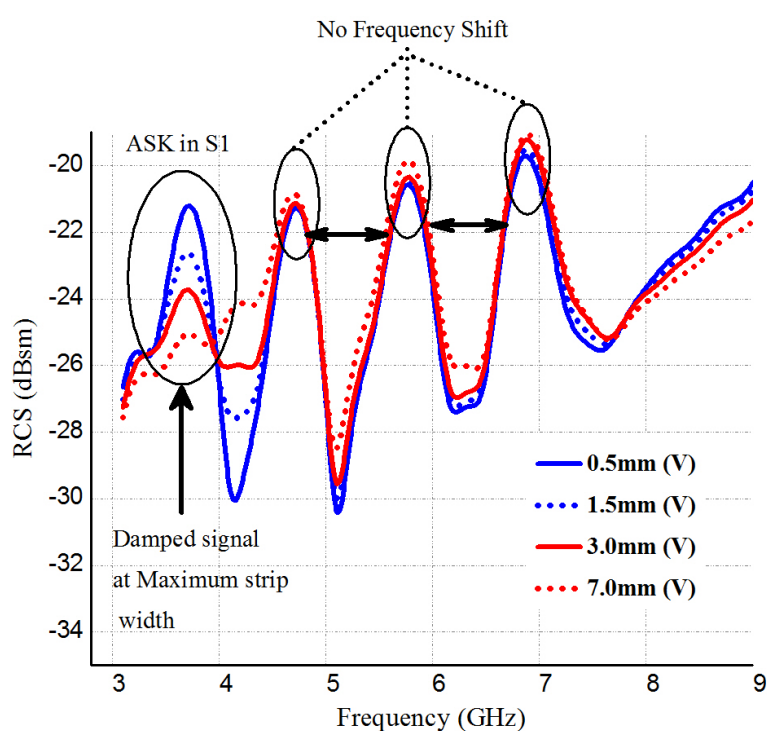

(a)

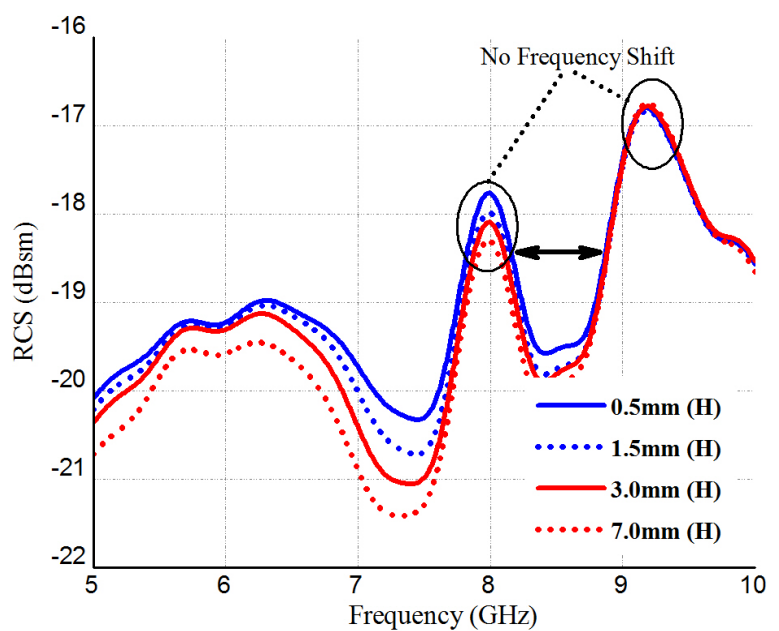

(b)

Fig. 7. Simulation results ASK implemented in S1 for PET substrate. (a) Vertical scatterers showing ASK in S1. (b) Horizontal scatterers.

duces the noise effects. Figures 7(a) and 7(b) show that using PET-based tag, neighboring peaks are less affected by noise; that's why over all tag capacity has been improved. Using values provided in Tab. 4 the calculated capacity of PET is 21 bits.

In the paper substrate, damping of resonating peaks is faster as compared to Kapton ${ }^{\circledR} H N$ and PET as shown in Fig. 8(a). It is observed that quality factor is affected, but still the tag is easily detectable [24], [25]. For the paper substrate the width of resistive strips are used $0.1 \mathrm{~mm}$ to $6 \mathrm{~mm}$ for $\mathrm{S} 1$, from $0.1 \mathrm{~mm}$ to $2 \mathrm{~mm}$ for $\mathrm{S} 2$, from $0.1 \mathrm{~mm}$ to $2.5 \mathrm{~mm}$ for $\mathrm{S} 3$, from $0.1 \mathrm{~mm}$ to $2.5 \mathrm{~mm}$ for $\mathrm{S} 4$, from $0.1 \mathrm{~mm}$ to $0.4 \mathrm{~mm}$ for both S5 and S6. Also, Figures 8(a) and $8(\mathrm{~b})$ show that there is no frequency shift on neighboring peaks because of amplitude variation in the first scatterer. This behavior is responsible for overall tag capacity enhancement. So using paper substrate, the tag capacity is calculated to be 24 bits.

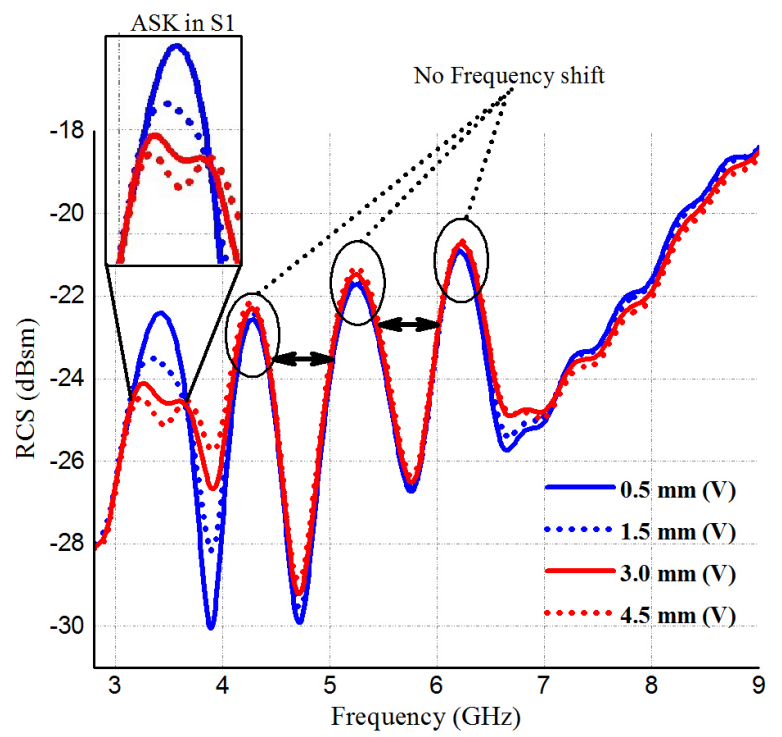

(a)

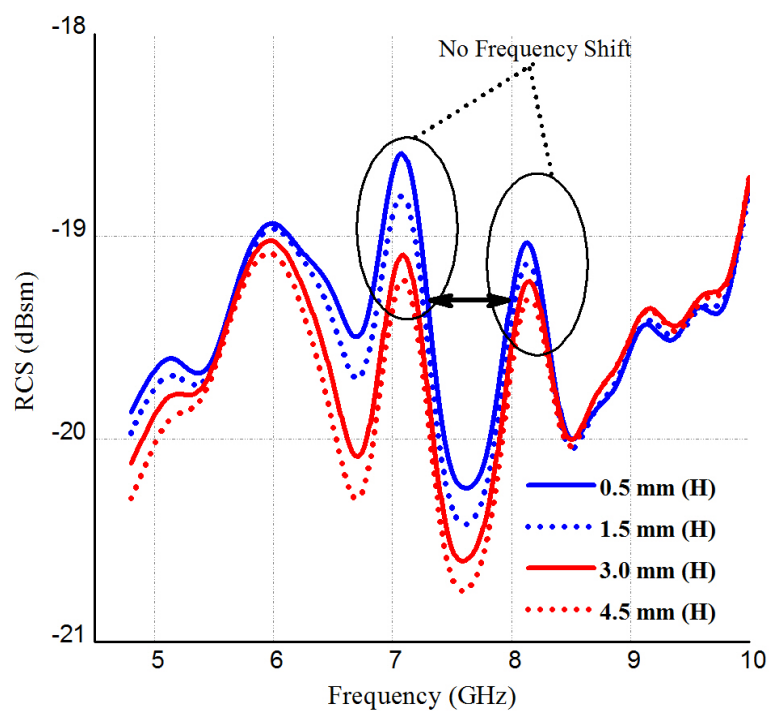

(b)

Fig. 8. Simulations results ASK implemented for scatterer 1 for the paper substrate. (a) Vertical resonators showing ASK in S1. (b) Horizontal scatterers.

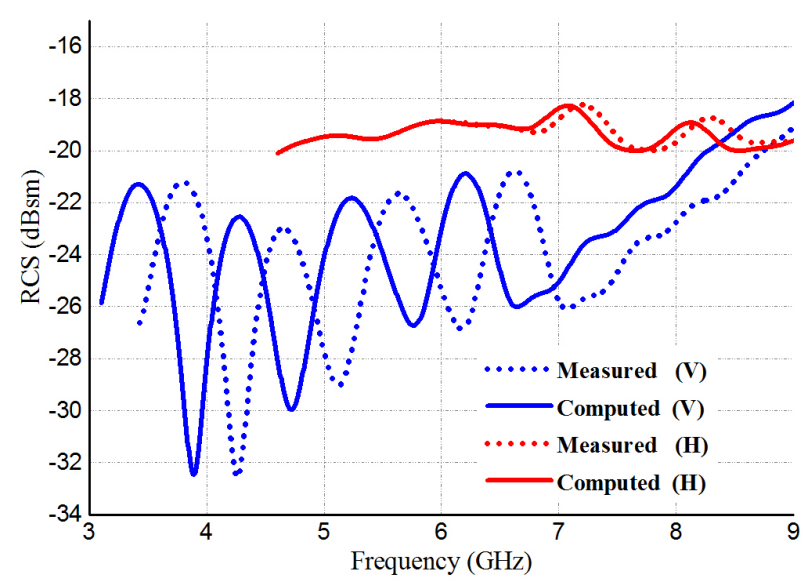

Fig. 9. Measured and computed results for the paper substrate. 


\begin{tabular}{|c|c|c|c|c|c|c|}
\hline Substrate & 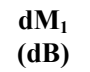 & $\begin{array}{l}\mathbf{d M}_{2} \\
(\mathbf{d B})\end{array}$ & $\begin{array}{l}\mathbf{d M}_{3} \\
(\mathbf{d B})\end{array}$ & $\begin{array}{l}\mathbf{d M}_{4} \\
(\mathbf{d B})\end{array}$ & $\begin{array}{l}\mathbf{d M}_{5} \\
(\mathrm{~dB})\end{array}$ & $\begin{array}{l}\mathbf{d M}_{6} \\
(\mathrm{~dB})\end{array}$ \\
\hline Kapton ${ }^{\circledR} H \mathrm{~N}$ & 0.58 & 0.362 & 0.339 & 0.296 & 0.45 & 1.244 \\
\hline PET & 0.56 & 0.17 & 0.15 & 0.37 & 0.53 & 0.1 \\
\hline Paper & 0.51 & 0.82 & 0.089 & 0.09 & 0.11 & 0.08 \\
\hline Substrate & $\begin{array}{l}\mathrm{Ma}_{1} \\
(\mathrm{~dB}) \\
\end{array}$ & $\begin{array}{l}M_{\mathrm{a} 2} \\
(\mathrm{~dB}) \\
\end{array}$ & $\begin{array}{l}M_{\mathrm{a} 3} \\
(\mathrm{~dB}) \\
\end{array}$ & $\begin{array}{l}M_{\mathrm{a} 4} \\
(\mathrm{~dB}) \\
\end{array}$ & $\begin{array}{l}M_{\text {a5 }} \\
(\mathbf{d B}) \\
\end{array}$ & $\begin{array}{l}M_{\mathrm{a} 6} \\
(\mathrm{~dB}) \\
\end{array}$ \\
\hline Kapton ${ }^{\circledR} H N$ & -20.09 & -21.8 & -22.25 & -19.6 & $\begin{array}{l}-17.9 \\
\end{array}$ & -18.33 \\
\hline PET & -19.89 & -21.18 & -20.69 & -19.89 & -17.57 & -16.96 \\
\hline Paper & -21.22 & -22.5 & -21.77 & -20.8 & -18.25 & -18.92 \\
\hline Substrate & $\begin{array}{l}\mathbf{M b}_{1} \\
\text { (dB) }\end{array}$ & $\begin{array}{l}M_{b 2} \\
\text { (dB) }\end{array}$ & $\begin{array}{l}M_{b 3} \\
(\mathbf{d B})\end{array}$ & $\begin{array}{l}M_{b 4} \\
(\mathbf{d B})\end{array}$ & $\begin{array}{l}M_{b 5} \\
(\mathrm{~dB})\end{array}$ & $\begin{array}{l}M_{\mathrm{b} 6} \\
(\mathrm{~dB})\end{array}$ \\
\hline Kapton ${ }^{\circledR} H N$ & -24.6 & -25.01 & -24.06 & -24.3 & -19.08 & -19.4 \\
\hline PET & -25.14 & -25.43 & -24.26 & -24.22 & -18.93 & -17.8 \\
\hline Paper & -25.08 & -26.08 & -24.26 & -24.09 & -19.03 & -19.59 \\
\hline
\end{tabular}

Tab. 4. Magnitude resolution and $M_{a}, M_{b}$ values for all substrates.

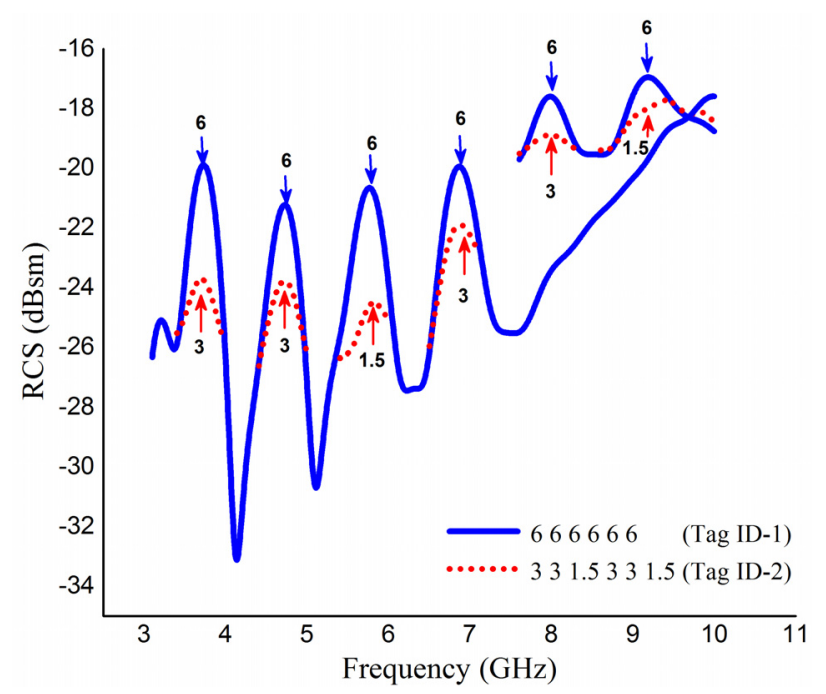

Fig. 10. ASK based coding principle.

The measured and computed results for a paper substrate with no resistive strip are shown in Fig. 9, which are in well coherence with computed values. The coding principle of the proposed tag configuration is based on ASK technique. Tag ID's for two different combinations are shown in Fig. 10. Likewise, multiple tag ID's can be generated to tag multiple objects.

\section{Conclusions}

Rhombic shaped broadband radiator's selectivity problem has been analyzed. For this purpose instead of conventional OOK, a unique Amplitude Shift Keying (ASK) has been applied. Keeping the size of chipless RFID within credit card format data encoding capacity has been increased. Environmental friendly 24-bit tag is realized. Scatterers are positioned in such a way that coupling effect is reduced to its minimum value. The tag design with three different substrates Kapton ${ }^{\circledR} H N$, PET and paper with same encoding techniques have been verified. These tags provide not only flexibility, meager cost expenditure but also easy to manufacture by printing techniques. Especially paper substrate based tag is highly suitable for green electronics and IoT applications. Future work emphasizes on the equipping tag with sensing capabilities using ASK.

\section{Acknowledgments}

This work was financially supported by Vinnova (The Swedish Governmental Agency for Innovation Systems) and University of Engineering and Technology, Taxila, Pakistan through the Vinn Excellence Centers program and ACTSENA research group funding, respectively.

\section{References}

[1] WANT, R., SCHILIT, B. N., JENSON, S. Enabling the internet of things. IEEE Journals and Magazines, 2015, vol. 48, no. 1, p. 28 to 35. DOI: 10.1109/MC.2015.12

[2] GUBBI, J., BUYYA, R., MARUSIC, S., et al. Internet of Things (IoT): A vision, architectural elements, and future directions. Future Generation Computer Systems, 2013, vol. 29, no. 7, p. 1645-1660. DOI: 10.1016/j.future.2013.01.010

[3] TRUONG, H. L., DUSTDAR, S. Principles for engineering IoT cloud systems. IEEE Cloud Computing, 2015, vol. 2, no. 2, p. 68 to 76. DOI: $10.1109 / \mathrm{MCC} .2015 .23$

[4] ISLAM, M., KARMARKAR, N. A novel compact printable dualpolarized chipless RFID System. IEEE Transactions on Microwave Theory and Techniques, July 2012, vol. 60, no. 7, p. 2142-2151. DOI: 10.1109/TMTT.2012.2195021

[5] OPREA, A., COURBAT, J., BARSAN, N., et al. Temperature, humidity and gas sensors integrated on plastic foil for low power applications. Sensors and Actuators B: Chemical, 2009, vol. 140, no. 1, p. 227-232. DOI: 10.1016/j.snb.2009.04.019

[6] NOOR, T., HABIB, A., AMIN, Y., et al. High-density chipless RFID tag for temperature sensing. Electronics Letters, 2016 , vol. 52, no. 8, p. 620-622.DOI: 10.1049/el.2015.4488

[7] ROSElli, L., MARIOTTI, C., MEZZANOTTE, P., et al. Review of the present technologies concurrently contributing to the implementation of the Internet of Things (IoT) paradigm: RFID, green electronics, WPT and energy harvesting. In 2015 IEEE Topical Conference on Wireless Sensors and Sensor Networks (WiSNet). San Diego (CA, USA), January 2015, p. 1-3. DOI: 10.1109/WISNET.2015.7127402

[8] DOBKIN, D., WANDINGER, T. The RF in RFID, UHF RFID in Practice. $2^{\text {nd }}$ edition. Waltham (USA): Newnes, 2013 (Chapter 3.) ISBN 9780123948304

[9] PRERADOVIC, S., KARMAKAR, N. Chipless RFID: Bar code of the future. IEEE Microwave Magazine, December 2010, vol. 11, no. 7, p. 87-97. DOI: 10.1109/MMM.2010.938571

[10] MCINTYRE, L., MICHAEL, K., ALBRECHT, K. RFID: Helpful new technology or threat to privacy and civil liberties. IEEE Potentials, September/October 2015, vol. 34, no. 5, p. 13-18. DOI: 10.1109/MPOT.2015.2410392

[11] PRERADOVIC, S., KARMAKAR, N .Design of fully printable planar chipless RFID transponder with 35-bit data capacity. In Proceedings of the 39th European Microwave Conference. Rome (Italy), 2009, p. 13-16. ISBN: 978-1-4244-4748-0. 
[12] TEDJINI, S., DUROC, Y. From radiator to signal processing antenna. In Asia-Pacific Microwave Conference 2011. Melbourne (Australia), 2011, p.175-178. ISBN: 978-1-4577-2034-5

[13] FAN.P. F., ZHOU, G. Z. Analysis of the business model innovation of the technology of Internet of Things in postal logistics. In 2011 IEEE 18Th International Conference on Industrial Engineering and Engineering Management (IE\&EM). Changchun (China), 2011, p. 532-536. ISBN: 978-1-61284-446-6. DOI: 10.1109/ICIEEM.2011.6035215

[14] BHUIYAN, S., KARMAKAR, N. Chipless RFID tag based on split-wheel resonators. In 2013 7th European Conference on Antennas and Propagation (EuCAP). Gothenburg (Sweden), 2013, p. 3054-3057. ISBN: 978-1-4673-2187-7

[15] REZAIESARLAK, R., MANTEGHI, M. Complex-naturalresonance-based design of chipless RFID tag for high-density data. IEEE Transactions on Antennas and Propagation. February 2014, vol. 62, no. 2, p. 898-904. DOI: 10.1109/TAP.2013.2290998

[16] VENA, A., BABAR, A. A., SYDÄNHEIMO, L., et al. A novel near-transparent ASK-reconfigurable inkjet-printed chipless RFID tag. IEEE Antennas and Wireless Propagation Letters, 2013, vol. 12, p. 753-756. DOI: 10.1109/LAWP.2013.2270932

[17] COSTA, F., GENOVESI, S., MONORCHIO, A. A chipless RFID based on multi resonant high-impedance surfaces. IEEE Transactions on Microwave Theory and Techniques, 2013, vol. 61 , no. 1, p. 146-153. DOI: 10.1109/TMTT.2012.2227777

[18] VENA, A., PERRET, E., TEDJINI, S. Chipless RFID tag using hybrid coding. IEEE Transactions on Microwave Theory and Techniques, December 2011, vol. 59, no. 12, p. 3356-3364. DOI: 10.1109/TMTT.2011.2171001

[19] BORTFELDT, J. The Floating Strip Micromegas Detector: Versatile Particle Detector for High Rate Applications. $1^{\text {st }}$ ed. Switzerland: Springer, 2015. ISBN 978-3-319-18892-8

[20] RANCE, O., SIRAGUSA, R., LEMAÎTRE-AUGER, P., et al. RCS magnitude coding for chipless RFID based on depolarizing tag. In 2015 IEEE MTT-S International Microwave Symposium. Phoenix (AZ, USA), 2015, p. 1-4. DOI: 10.1109/MWSYM.2015.7166929

[21] IONESCU, C., SVASTA, P., VASILE, A., et al. Investigations on organic printed resistors based on PEDOT: PSS. In 2012 IEEE 18th International Symposium on Design and Technology in Electronic Packaging (SIITME). Alba Iulia (Italy), 2012, p. 85-89. DOI: 10.1109/SIITME.2012.6384352

[22] HAVLICEK, J., SVANDA, M., MACHAC, J., et al. Improvement of reading performance of frequency-domain chipless RFID transponders. Radioengineering, June 2016, vol. 25, no. 2, p. 219 to 229. DOI: $10.13164 / \mathrm{re} .2016 .0219$

[23] LEI XU, KAMA HUANG. Design of compact trapezoidal bow-tie chipless RFID tag. International Journal of Antennas and Propagation, October 2014, vol.2015, Article ID 502938, 7 p. DOI: $10.1155 / 2015 / 502938$

[24] FENG, Y., XIE, L., CHEN, Q., et al. Low-cost printed chipless RFID humidity sensor tag for intelligent packaging. IEEE Sensors
Journal, 2015, vol. 15, no. 6, p. 3201-3208. DOI: 10.1109/JSEN.2014.2385154

[25] JAVED, N., HABIB, A., AMIN, Y., et al. Directly printable moisture sensor tag for intelligent packaging. IEEE Sensors Journal, June 2016, vol. 16, no. 16, p. 6147-6148. DOI: 10.1109/JSEN.2016.2582847

\section{About the Authors...}

Ayesha HABIB is working as a research scholar at Telecommunication Engineering Dept., University of Engineering and Technology Taxila, Pakistan. Currently, she is pursuing her Ph.D. in chipless RFID domain. She is a member of IEEE and IEICE.

Sohaira ANSAR received her B.Sc. degree in Telecom Engineering from the University of Engineering and Technology (UET), Taxila in 2014. In the same year, she joined UET, Taxila as Ms research scholar.

Adeel AKRAM is a Dean and Professor of Telecommunication \& Information Engineering Dept., University of Engineering and Technology Taxila, Pakistan. He is leading a 5G Wireless Communication research group at UET Taxila, Pakistan.

Muhammad Awais AZAM received his Ph.D. degree in Pervasive and Ubiquitous Computing from London, UK in 2012. He is working as an Assistant Professor at the Dept. of Computer Engineering, UET Taxila, Pakistan.

Yasar AMIN is a Chairman and Associate Professor of Telecommunication Engineering Dept., University of Engineering and Technology Taxila, Pakistan. He is founder of ACTSENA Research Group at UET Taxila, Pakistan. Dr. Yasar is a member of IEEE, IET, ACM and ACES.

Hannu TENHUNEN is a Chair Professor of Electronic Systems at the Royal Institute of Technology (KTH), Stockholm, Sweden. Prof. Tenhunen has held professor position as full professor, invited professor or visiting honorary professor in Finland (TUT, UTU), Sweden (KTH), USA (Cornel U), France (INPG), China (Fudan and Beijing Jiatong Universities), and Hong Kong (Chinese University of Hong Kong), and has an honorary doctorate from Tallinn Technical University. Prof. Tenhunen is a member of the Academy of Engineering Science of Finland. 